Article

\title{
Vibration Reduction in a Pulse Tube-Cooled High Purity Germanium Detector
}

\author{
Hongyan Wei ${ }^{1,2}$, Yuqiang Xun ${ }^{1, *}$, Jinghui Cai ${ }^{1}$ and Lijuan Wang ${ }^{1}$ \\ 1 Key Laboratory of Technology on Space Energy Conversion, Technical Institute of Physics and Chemistry, \\ CAS, Beijing 100190, China; weihongyan@mail.ipc.ac.cn (H.W.); jhcai@mail.ipc.ac.cn (J.C.); \\ wanglijuan@mail.ipc.ac.cn (L.W.) \\ 2 University of Chinese Academy of Sciences, Beijing 100049, China \\ * Correspondence: yqxun@mail.ipc.ac.cn
}

check for

updates

Citation: Wei, H.; Xun, Y.; Cai, J.; Wang, L. Vibration Reduction in a Pulse Tube-Cooled High Purity Germanium Detector. Appl. Sci. 2022, 12, 1827. https://doi.org/10.3390/ app12041827

Received: 1 January 2022

Accepted: 1 February 2022

Published: 10 February 2022

Publisher's Note: MDPI stays neutral with regard to jurisdictional claims in published maps and institutional affiliations.

Copyright: (c) 2022 by the authors. Licensee MDPI, Basel, Switzerland. This article is an open access article distributed under the terms and conditions of the Creative Commons Attribution (CC BY) license (https:// creativecommons.org/licenses/by/ $4.0 /)$.

\begin{abstract}
High-purity germanium (HPGe) is a vibration-sensitive, high-resolution detector. It has been found that microphonic noise induced by vibration and electromagnetic interference from EMC causes energy resolution degradation in HPGe detectors. In this paper, to enhance the energy resolution of a pulse tube-cooled high purity germanium detector, a passive vibration isolation system for the portable pulse tube cooler (PTC) was employed and investigated. In order to evaluate the performance of the vibration isolation system, micro-vibration tests of the compressor with a vibration isolation kit and detector mounting interface were performed. Meanwhile, detector energy resolution and detector signal noise were tested, respectively, under the PTC, with the isolation system switched to either an on or off condition. The test results indicate that the effectiveness of passive vibration isolation techniques is confirmed, and no degradation was induced by PTC vibration on detector energy resolution.
\end{abstract}

Keywords: portable pulse tube cooler; vibration; reduce vibration; high purity germanium detector

\section{Introduction}

HPGe detectors are the laboratory standard for high-resolution gamma-ray spectroscopy and are used extensively in a wide range of application areas, such as environmental monitoring, medicine, geology and scientific research [1]. In order to reduce the leakage of current-induced noise from thermal generation of charge carriers, HPGe detectors need to operate at a temperature range of $90 \sim 120 \mathrm{~K}$. To achieve these temperatures, liquid nitrogen (LN2), a cryogen, was commonly used with a cryostat. However, cryogen use is confronted with several health risks and operational problems [2]. Electromechanical cooling is an attractive choice, especially for portable HPGe detectors. Advances in Joule-Thomson technology coupled with HPGe detectors have been reported [3]. Electromechanical cooling systems (cryocooler) have become common for HPGe detectors.

HPGe detector resolution is a measure of the width, specifically the full width at half maximum (FWHM), of a single energy peak, expressed in absolute keV. Better (lower FWHM value) resolution enables the system to more clearly separate the peaks within a spectrum. Mechanically cooled HPGe detector resolution performance is typically specified as degradation by some percentage compared to LN2 performance.

The cryocooler essentially needs pressure oscillation to generate low temperatures. Gas pressure oscillation intrinsically causes vibrations at the cold stage of the cryocooler. Mechanical vibrations inherent in EMC cause electrical noise induced at the preamplifier input and periodic changes of structural capacitances between the HPGe detector and components. The vibration alters the capacitances in input circuits of the preamplifier, causing electrical interference, and causing the detector performance to degrade.

Many technologies have been developed to reduce the micro-vibration induced by coolers [4-8]. Riabzev et al. [5] developed the ultra-low vibration cryogenic cooler by 
utilizing a combination of passive and active suppression techniques. The effectiveness of the techniques is mainly reflected in the axial direction of the cooler. Riabzev et al. [6] proposed a multidimensional, triple-stage, passive vibration isolator on the cold tip of a small cryogenic cooler. The isolator is used to attenuate cold-tip vibration; however, vibration induced by the compressor inevitably passes to the cold tip when the compressor and cold finger are fixed in the same platform. Kwon et al. [7] proposed an SMA blade isolator that ensures desirable vibration isolation performance, except in the gravitational axis, regardless of $1 \mathrm{G}$ and $0 \mathrm{G}$ conditions. The isolator has high stiffness in order to support the cooler in the gravitational axis. Thus, the isolator cannot isolate vibration in the gravitational axis. Kwon et al. [8] proposed a multilayered blade isolator with doublesided adhesive tape, and this isolator can provide a constant vibration isolation capability irrespective of gravitational effects. Although the applicability and survivability of doublesided adhesive tapes were evaluated through qualification-level TV tests, the long-term stability and reliability of double-sided adhesive tape is unconvincing. Oh $\mathrm{H} \mathrm{U}$ et al. [4] proposed a passive isolation system named PLOVIS, and PLOVIS is used to isolate vibration from the cooler. However, the isolator requires an additional $1 \mathrm{G}$ compensation device to obtain an ideal micro-vibration isolation capability on the ground.

In this paper, a portable PTC, suitable for HPGe detectors, was developed. A split PTC was used to maintain the cryogenic temperature. The split PTC consisted of a linear compressor and cold head. Degradation of detector performance was suppressed in two ways. A portable pulse tube cryocooler (PTC) was expected to function as a low-vibration cryocooler. Due to the absence of moving components in the cold head, the split PTC could provide a cryogenic temperature with low vibration. Compressors are well-known sources of harmonic disturbance. In order to attenuate the vibration exported, a linear dual-piston compressor comprised a pair of back-to-back in-line pistons resonantly driven by linear "moving coil" motors, arranged to oppositely slide inside tightly matched cylinder liners. A flexible gas transfer line (a thin-walled copper tube of a small diameter) was installed to connect the linear compressor and cold head. The flexible gas transfer line isolated the detector vibration interference. Although producing quite acceptable vibration export for most applications, this vibration export was excessive for the HPGe detector. In order to attenuate cooler vibration further, a compressor vibration isolation kit (CVIK) and heat links [9-12] were implemented.

On account of the advantages of the simplicity and reliability of passive-type isolators, they have generally been employed to achieve the desired isolation performance. To attenuate the micro-vibration of the compressor, a compressor vibration isolation kit (CVIK) with eight sets of spring and damper isolators was implemented. Eight sets of damping spring dampers were divided into two groups and distributed evenly around the compressor. The right section of Figure 1 shows a structural diagram. The compressor with the CVIK had the same isolation performance in any direction.
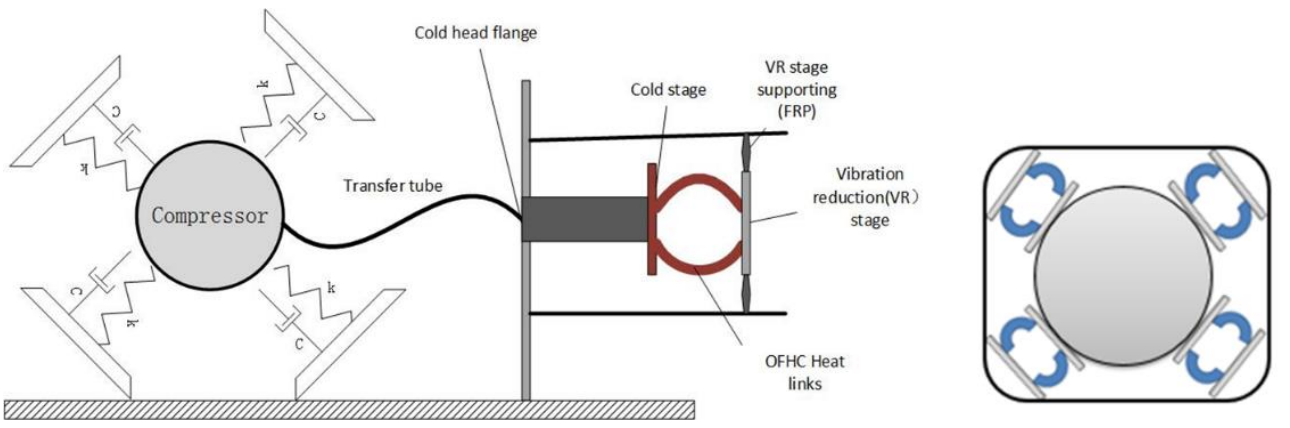

Figure 1. Portable EMC vibration reduction system for HPGe detector. 
This paper evaluates the effectiveness of the CVIK and heat links. A micro-vibration test and HPGe energy resolution tests were performed. The results indicate that the passive isolation method can meet HPGe detector requirements.

\section{Passive Isolation System Design}

In this paper, the specifications for the low-vibration portable EMC system are displayed in Table 1. A schematic illustration of the portable passive isolation PTC system is shown in Figure 1. The compressor assembly was mainly composed of a compressor, spring isolators, housing for the compressor, and an " $\mathrm{S}$ " shape transfer line. The transfer line connected the cold flange with the compressor. The spring isolators attenuated base plate and cold head flange vibration. To attenuate detector interface (VR stage) vibration, copper heat links were used to connect the cold tip with detector interface. An FPR-supporting plate [13] was mounted on a vacuum vessel flange to support the HPGe detector.

Table 1. The specifications for the low-vibration portable EMC system.

\begin{tabular}{cc}
\hline Item & Specification \\
\hline Compressor power consumption & $80 \mathrm{~W}$ \\
Cooling performance requirement & $4 \mathrm{~W} @ 80 \mathrm{~K}$ \\
Power frequency & $64 \mathrm{~Hz}$ \\
Cooler power controller (CPC) modulation frequency & $100 \mathrm{kHz}$ \\
Working orientation & Multi-orientation operation \\
Transport standard & $2 \mathrm{~g}$ \\
HPGe efficiency & $40 \%$ \\
Typical cooldown time & $6 \mathrm{~h}$ \\
\hline
\end{tabular}

To reduce PTC mounting base plate vibration, a CVIK was installed between the compressor and the PTC-mounted interface. In order to ensure cooler multi-orientation operation, the CVIK included eight sets of spring and damper isolators to reduce the transmission of vibration from the compressor. The transmission of the vibration force $\eta$ is defined as the ratio between the force at the mounted interface and the force exported by the compressor. For a linear single-degree-of-freedom spring and damper system, $\eta$ is expressed as Equation (1). Figure 2 demonstrates the physical model.

$$
\begin{gathered}
\eta=\frac{F_{\max }}{F_{o}}=\sqrt{\frac{1+(2 \varepsilon \lambda)^{2}}{\left(1-\lambda^{2}\right)^{2}+(2 \varepsilon \lambda)^{2}}} \\
|X|=\frac{|F|}{k} \eta
\end{gathered}
$$

where $\varepsilon$ is a damping ratio, $\lambda$ is the ratio of vibrational frequency and natural frequency of the spring, $F_{\text {max }}$ is the amplitude of vibration force after the vibration isolators, $F_{0}$ is the amplitude of vibration force from the vibration source, $|F|$ is vibration force amplitude, $|X|$ is the isolation system vibration defection, and $\mathrm{k}$ is the axis stiffness of the CVIK.

In order to ensure $\eta \leq 0.1$, the CVIK design parameters are shown in Table 2 . The natural frequency of a compressor with the CVIK is less than $12.7 \mathrm{~Hz}$. The axis stiffness of the CVIK is $16,000 \mathrm{~N} / \mathrm{m}$. The transfer line deflection is within $3.52 \mathrm{~mm}$ under the $2 \mathrm{~g}$ sine vibration load. Figure 3 shows the transmissibility of the CVIK at different vibrational frequencies. The figure indicates that the transmissibility is 0.07 at the main frequency 64 $\mathrm{Hz}$ and that the CVIK has lower transmissibility at harmonic frequency. The requirement of the CVIK is not only to reduce vibration transmissibility but also to weaken the vibration displacement under the $2 \mathrm{~g}$ sine vibration load. According to function 2, the displacement of the compressor is $3.52 \mathrm{~mm}$ (which the copper transfer line tube can bear) when the PTC suffers from $2 \mathrm{~g}$ acceleration impact. 


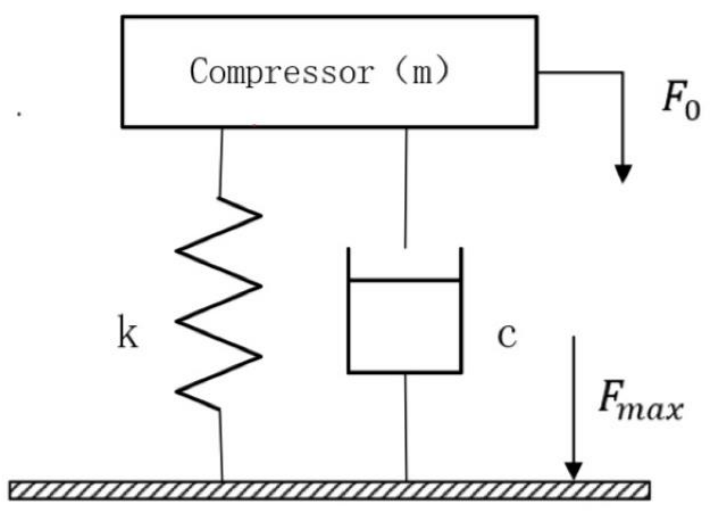

Figure 2. The physical model of the linear single-degree-of-freedom spring and damper system.

Table 2. The compressor isolation system parameters.

\begin{tabular}{cc}
\hline Item & Parameters \\
\hline Compressor mass (contain fixed structure) & $3.0 \mathrm{~kg}$ \\
Spring isolator damping ratio & 1.3 \\
Isolation system vertical stiffness & $16,000 \mathrm{~N} / \mathrm{m}$ \\
Isolation system horizontal stiffness & $16,000 \mathrm{~N} / \mathrm{m}$ \\
Isolation system axial stiffness & $16,000 \mathrm{~N} / \mathrm{m}$ \\
Isolation system natural frequency & $12.7 \mathrm{~Hz}$ \\
Compressor operating frequency & $64 \mathrm{~Hz}$ \\
Vertical vibration displacement with 1 N force(operating) $/ 2 \mathrm{~g}$ & $0.0088 \mathrm{~mm} / 3.52 \mathrm{~mm}$ \\
acceleration impact (transport standard) & $0.0088 \mathrm{~mm} / 3.52 \mathrm{~mm}$ \\
Horizontal displacement of compressor & $0.0088 \mathrm{~mm} / 0.45 \mathrm{~mm}$ \\
Axial displacement of compressor &
\end{tabular}

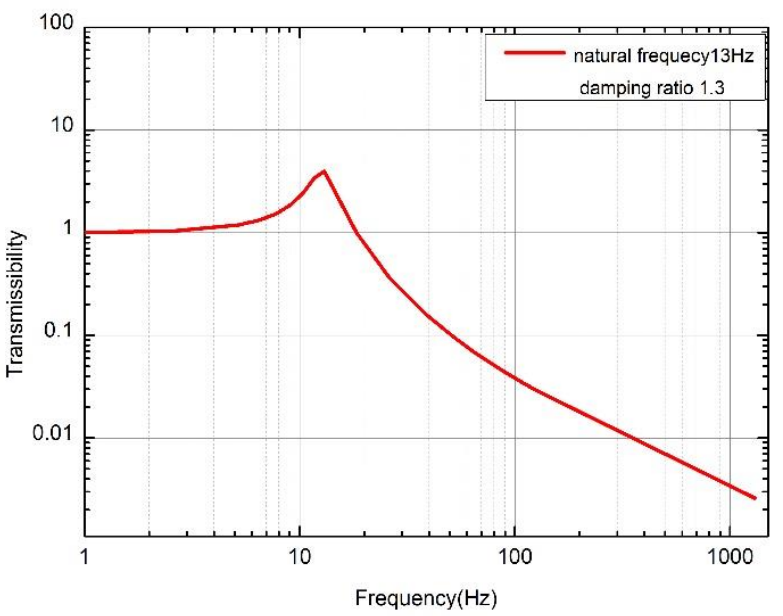

Figure 3. The transmissibility of the compressor isolation system.

In this paper, the ultimate requirement was to reduce the vibration of the HPGe detector mounted interface. Especially, HPGe detectors need to extend cold tips because detectors require lead chamber shielding in use. The longer the copper cold tip, the greater the vibration of the detector interface.

The CVIK ensured the attenuation of the vibration of the compressor-mounted interface and the cold head flange. In order to further mitigate detector vibration, oxygen-free high-conductivity copper heat links and a glass fiber-reinforced-plastic supporting plate were used. The heat links consisted of several copper wires, each $0.5 \mathrm{~mm}$ in diameter, which reduced the heat links' spring constant. The detector interface was thermally connected to the cold tip by the heat links, and the HPGe detector was mounted on a vibration reduction 
stage. An FPR plate was used to support the detector. One end of the FPR plate was mounted on a vacuum vessel flange, and the other end supported the detector. Thus, detector vibration was obtained from the cold head flange and heat links. Additionally, we bent the transfer line into an "S" shape, which may have reduced the transfer line stiffness to decrease the compressor vibration transmissibility to the cold head flange. The advantage of the heat links was verified experimentally.

\section{Evaluation Performance of the PTC Vibration Isolation System}

The PTC vibration isolation system was evaluated both on the PTC and the HPGe detector. A three-dimensional dynamometer force sensor (Kistler 9257B) was used to measure compressor vibration [14]. A PCB three-dimensional piezoelectric accelerometer (PCB 356B18) was installed to measure detector interface vibration acceleration. Meanwhile, detrimental effects of the PTC from mechanical vibration on spectrometric performance and detector signal noise were tested.

In order to evaluate CVIK performance, an isolation performance test on a Kistler 9257B table was executed. Figure 4 shows the compressor isolation performance test configuration on the Kistler 9257B. The compressor with CVIK was mounted on the Kistler $9257 \mathrm{~B}$, and a cooler finger was rigidly fixed on other base plate on a sponge mat. The " $\mathrm{S}$ " shape copper transfer line may have affected the transmissibility of the cooler finger. The compressor vibration level was tested under the rigid connection and vibration isolation connection of the compressor. To provide a lightweight PTC system for the HPGe detector, the compressor and cold finger inevitably needed to be fixed to the same base plate. Thus, the vibration performance of the compressor with CVIK and cooler finger mounted in the same plate needed to be evaluated.

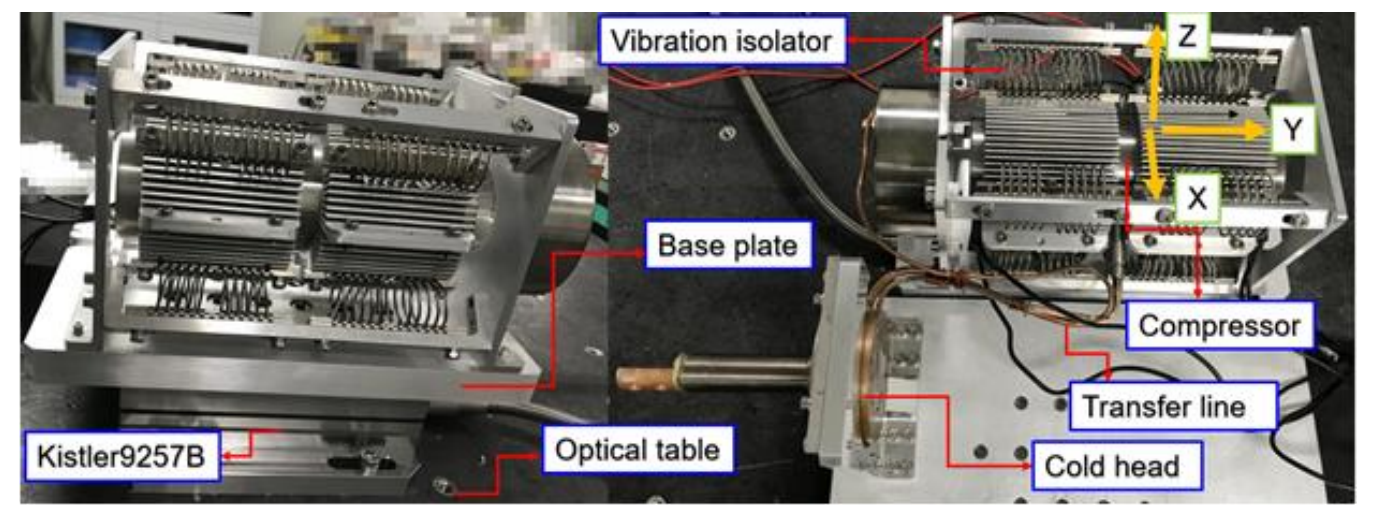

Figure 4. Test configuration of the compressor isolation performance on the Kistler9257B.

Figure 5 illustrates the vibration transmissibility of the CVIK. The compressor was driven by $64 \mathrm{~Hz}, 50 \mathrm{~W}$ AC. The percentages in the figure indicate the ratio of compressor vibration force with and without the CVIK. The vibration peak value of the rigid condition was less than $1 \mathrm{~N}$, and the peak value of the isolation condition was less than $0.1 \mathrm{~N}$. The figure indicates the vibration level without the CVIK was higher in harmonic frequency because the higher frequency modes were excited. CVIK transmissibility was less than $10 \%$ in higher-frequency modes. The main frequency vibration transmissibility was higher than theoretical calculation for some reason, such as the transfer line stiffness affecting CVIK nature frequency and gas reservoir vibration. However, the main frequency vibration force was smaller, which met the requirement of less than $0.2 \mathrm{~N}$. Figure 6 shows the isolation performance of the PTC when the compressor and cold finger were mounted on the same plate. The figure indicates that the vibration force of the PTC without an isolation system was up to $4 \mathrm{~N}$, and the isolation performance was basically the same as the compressor. 

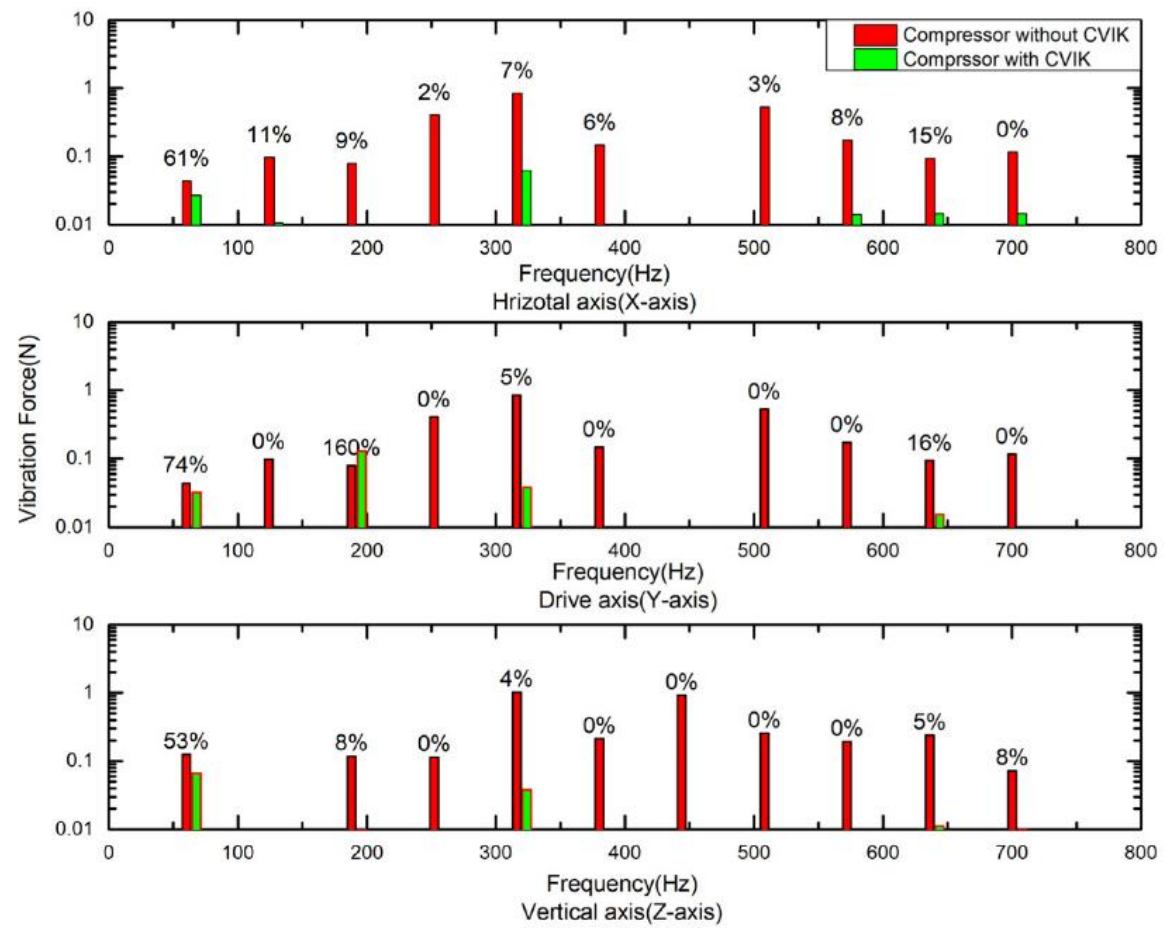

Figure 5. Comparison of compressor vibration level with and without an isolation system.

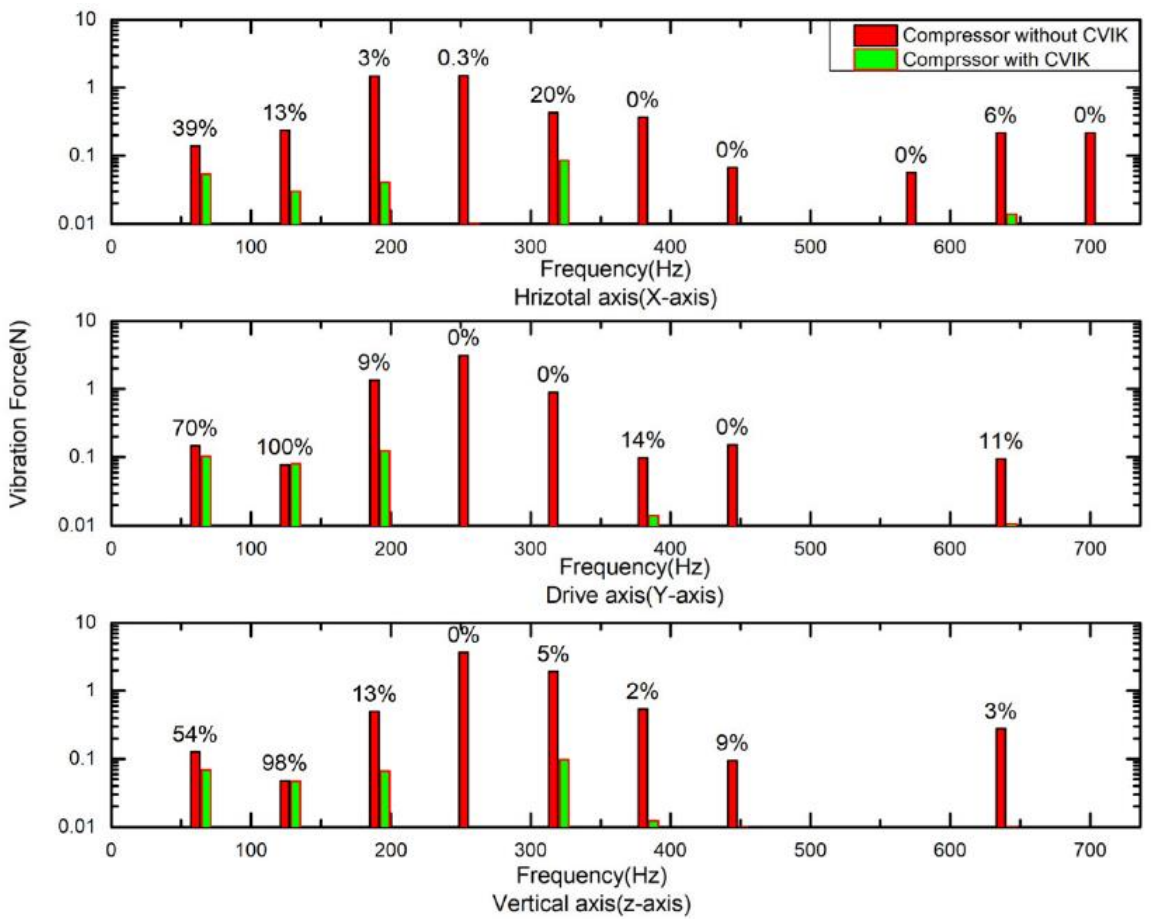

Figure 6. Comparison of PTC vibration level with and without a compressor isolation system.

Table 3 shows the experimental results for the root mean square value (Nrms) of the vibration force of the compressor, PTC, and cold finger with and without the CVIK obtained from the time domain profiles. Vibration RMS of the compressor with CVIK was less than $0.15 \mathrm{Nrms}$, and the transmissibility was less than $6 \%$. The cooler vibration force RMS was unamplified after compressor vibration isolation. The RMS of the PTC with CVIK was less than $0.15 \mathrm{Nrms}$, and the transmissibility was less than $6 \%$, which met the HPGe requirement of less than $0.2 \mathrm{Nrms}$. 
Table 3. Isolation performance test results summary.

\begin{tabular}{cccccccc}
\hline Case & \multicolumn{3}{c}{ Without Vibration } & \multicolumn{3}{c}{ With Vibration } \\
\hline axis & $\mathbf{x}$ & $\mathbf{y}$ & $\mathbf{z}$ & $\mathbf{x}$ & $\mathbf{y}$ & $\mathbf{z}$ \\
\hline $\begin{array}{c}\text { Compressor } \\
\text { RMS value (Nrms) } \\
\quad \text { PTC }\end{array}$ & 0.83 & 1.81 & 1.05 & 0.06 & 0.25 & 0.05 \\
$\begin{array}{c}\text { RMS value (Nrms) } \\
\text { Cold finger } \\
\text { RMS value (Nrms) }\end{array}$ & 1.64 & 2.57 & 3.10 & 0.09 & 0.14 & 0.11 \\
\hline
\end{tabular}

In this section, we focus on the evaluation of detector mounting interface vibration attenuation by introducing heat sinks. Detector mounting interface vibration came from heat links and the FPR-supporting plate. Since the cold tip and detector mounting interface were hard to mount on the Kistler 9257B, a PCB three-dimensional piezoelectric accelerometer was chosen for evaluation of heat link vibration isolation performance. Figure 7 shows an assembly drawing of the heat links and accelerometer mounting positions. Two measurement cases were performed under the CVIK: for case 1, the base plate, cold head flange and cold tip vibration acceleration were tested; for case 2, the accelerometer was moved to the detector mounting interface from the cold tip and the other two accelerometers stayed the same. The ratio of vibration acceleration of the detector mounting interface to vibration acceleration of the cold tip was used to evaluate the vibration isolation performance of the heat links. Base plate and cold head flange acceleration were used to monitor case 1 and case 2 in consistent test conditions. Figure 8 shows the vibration isolation performance of heat links; the percentages were the ratio of detector mounting interface vibration to cold tip vibration. Vibration acceleration peak values of the detector mounting interface were less than $5 \mathrm{mg}$ in main frequency and harmonic frequency. Heat links effectively attenuate the vibration in higher frequency modes. Table 4 shows the different position and different measurement case time profile RMS test results. The detector interface vibration came from the heat links and the FPR-supporting plate. Table 3 indicates that the detector vibration level was similar to the cold head flange. Thus, the transmissibility of the cold tip was very low, which indicates that heat links were effective in reducing the vibration transmission of the cold tip. The ratios of detector mounting interface to cold tip $\mathrm{a}_{\mathrm{rms}}$ (root mean square of acceleration) were $26.8 \%, 15.6 \%$, and $74 \%$ in the $\mathrm{x}, \mathrm{y}$, and $\mathrm{z}$ axes. The detector vibration interface $\mathrm{a}_{\mathrm{rms}}$ was less than $10 \mathrm{mg}_{\mathrm{rms}}$, which met HPGe detector requirements.

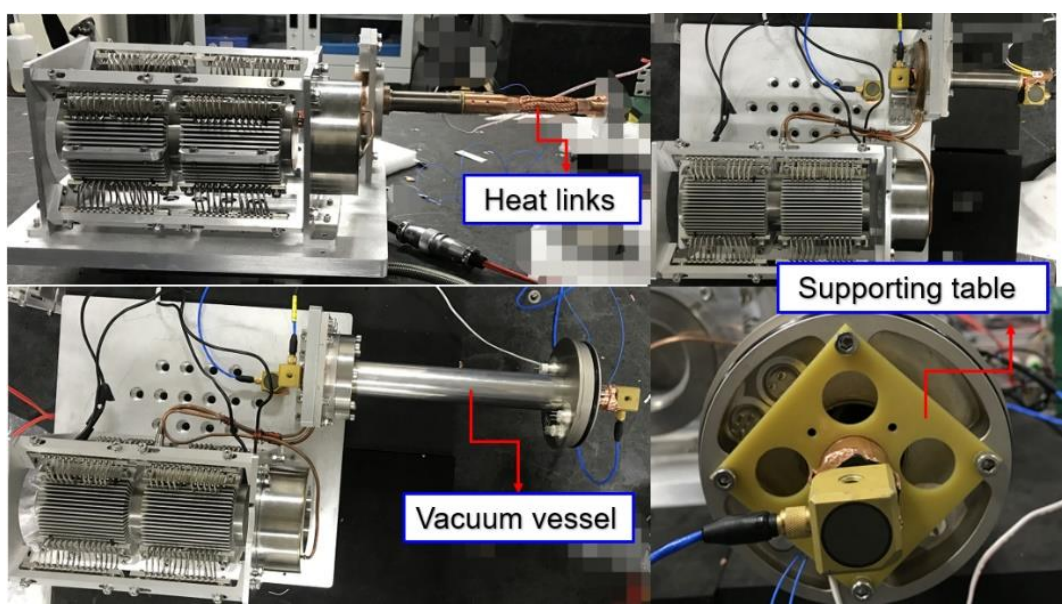

Figure 7. Test configuration for testing VR stage vibration isolation performance. 


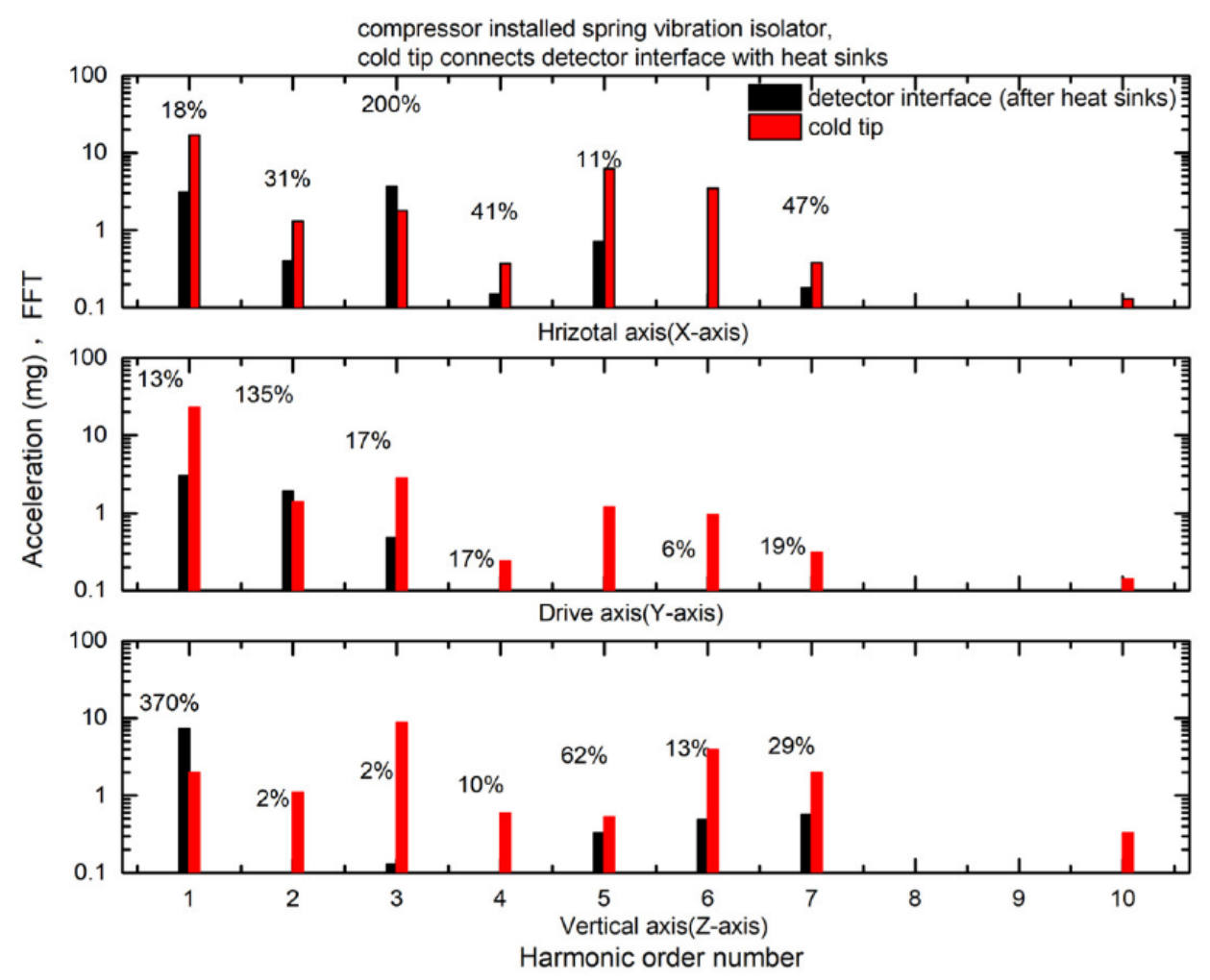

Figure 8. Detector interface vibration isolation performance.

Table 4. Heat links isolation performance measurement results summary.

\begin{tabular}{|c|c|c|c|c|c|c|}
\hline \multirow{2}{*}{ Position } & \multicolumn{3}{|c|}{ Case1 } & \multicolumn{3}{|c|}{ Case2 } \\
\hline & $\mathbf{x}$ & $\mathbf{y}$ & $\mathbf{z}$ & $\mathbf{x}$ & $\mathbf{y}$ & $\mathbf{z}$ \\
\hline $\begin{array}{l}\text { Base plate } \\
\left(\mathrm{mg} g_{\text {rms }}\right)\end{array}$ & 5.1 & 4.9 & 8.5 & 4.9 & 4.3 & 5.9 \\
\hline Cold head flange ( $\mathrm{mg}_{\mathrm{rms}}$ ) & 7.7 & 4.2 & 7.8 & 8.5 & 3.3 & 6.7 \\
\hline Cold tip $\left(\mathrm{mg}_{\mathrm{rms}}\right)$ & 20.9 & 27.5 & 11.4 & & & \\
\hline Detector interface (mgrms) & & & & 5.6 & 4.3 & 8.4 \\
\hline
\end{tabular}

To estimate the effect of mechanical vibrations from the PTC on detector energy resolution, the detector resolution and the detector signal spectrum characteristic were compared under the PTC switched on or off [15]. The thermal inertia of the detector was large enough to allow tests to be taken over a period of $10 \mathrm{~min}$, with little change in detector temperature.

Figure 9 illustrates that the detector signal noise was the same range from $0 \mathrm{~Hz}$ to $2000 \mathrm{~Hz}$ with the PT cooler switched on and switched off. Figure 9 indicates that the vibration of the PTC basically provided no microphone noise for the detector signal. Thus, in this paper, the vibration isolation system of the PTC met the requirement of the HPGe detectors. Figure 10 shows that detector FWHM energy resolutions of $1.31 \mathrm{keV}$ and $1.98 \mathrm{keV}$ were achieved at $122 \mathrm{keV}$ and $1332 \mathrm{keV}$, respectively, with the cooler switched on. Figure 11 indicates the resolution improved to $1.0 \mathrm{keV}$ and $1.84 \mathrm{keV}$ at $122 \mathrm{keV}$ and $1332 \mathrm{keV}$, respectively, under the PTC switched off. Table 5 summarizes the detector energy resolution under LN2, PT cooler on and PT cooler off conditions. Under the LN2 and PT cooler off conditions, the detector energy resolution was basically equal. The energy resolution degraded $2.5 \%$ and $8.3 \%$ at $1332 \mathrm{keV}$ and $122 \mathrm{keV}$, respectively. Microphone noise and electromagnetic interference were introduced simultaneously when the cooler was on. Electromagnetic interference was the main reason for degrading detector energy 
resolution when the vibration isolation system and heat links were introduced to the PTC in this paper.

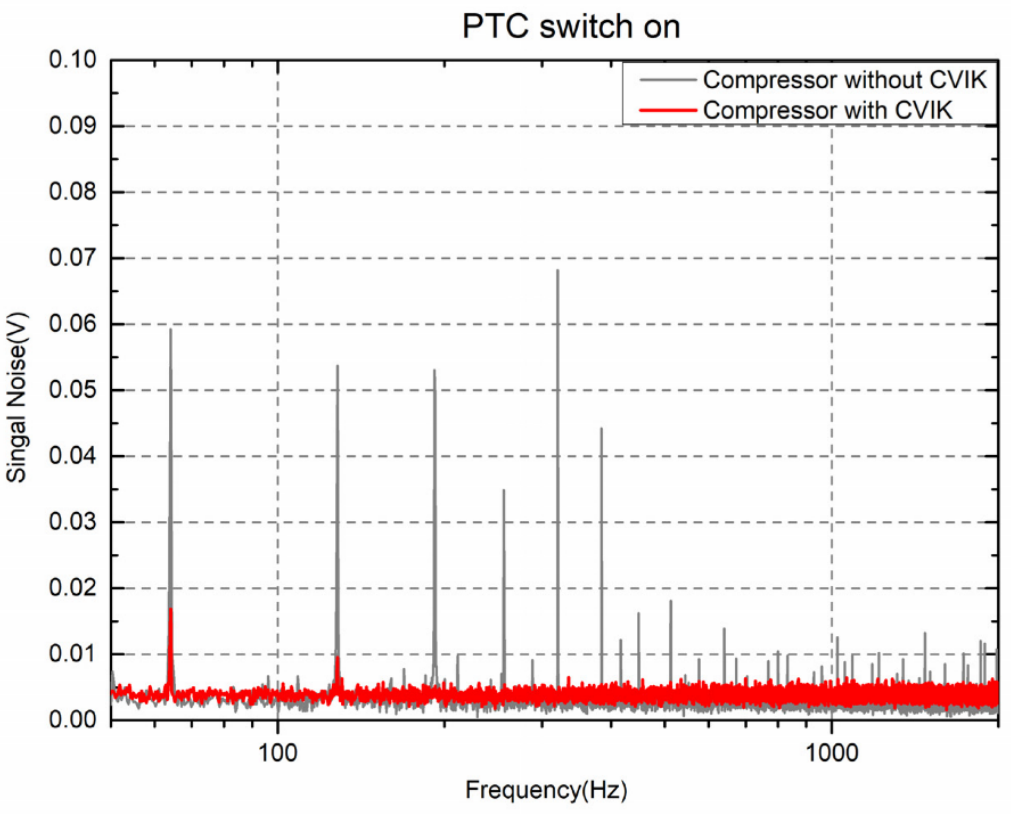

Figure 9. PTC switched on detector signal noise.

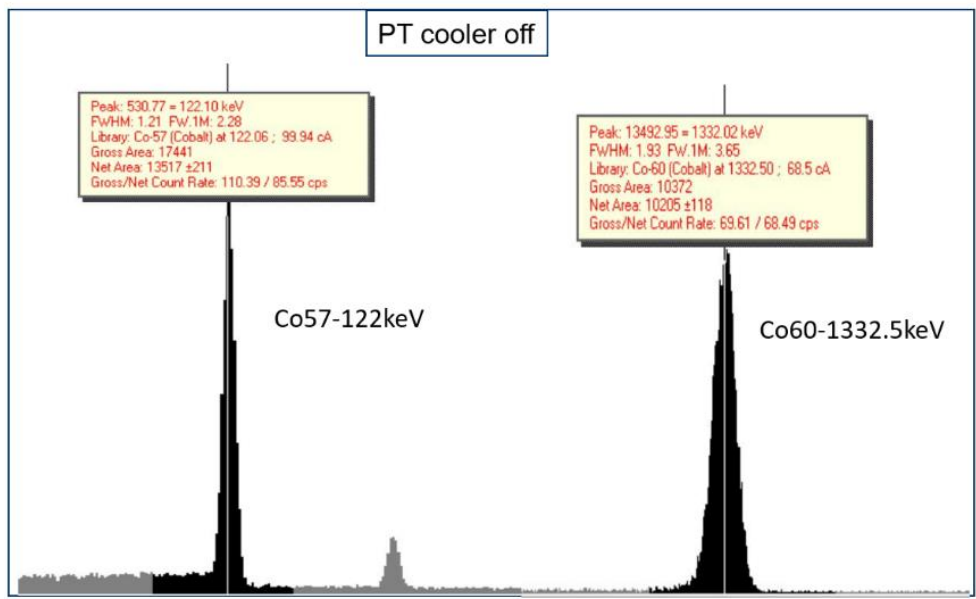

Figure 10. Co60 and Co57 energy resolution with PTC switched off.

Table 5. Heat links isolation performance measurement results.

\begin{tabular}{cccc}
\hline \multirow{2}{*}{$\begin{array}{c}\text { Energy Resolution } \\
\text { @ }\end{array}$} & \multicolumn{4}{c}{$\mathbf{4 0 \%}$ Rel. Eff. HPGe Coaxial-p-Type Detector (keV) } \\
\cline { 2 - 4 } & LN2 & PTC off & PTC on \\
\hline $1332 \mathrm{keV}$ & 1.90 & 1.93 & 1.98 \\
$122 \mathrm{keV}$ & 1.15 & 1.21 & 1.31 \\
Detector temperature $(\mathrm{K})$ & 88 & $80 \sim 82$ & 80 \\
\hline
\end{tabular}




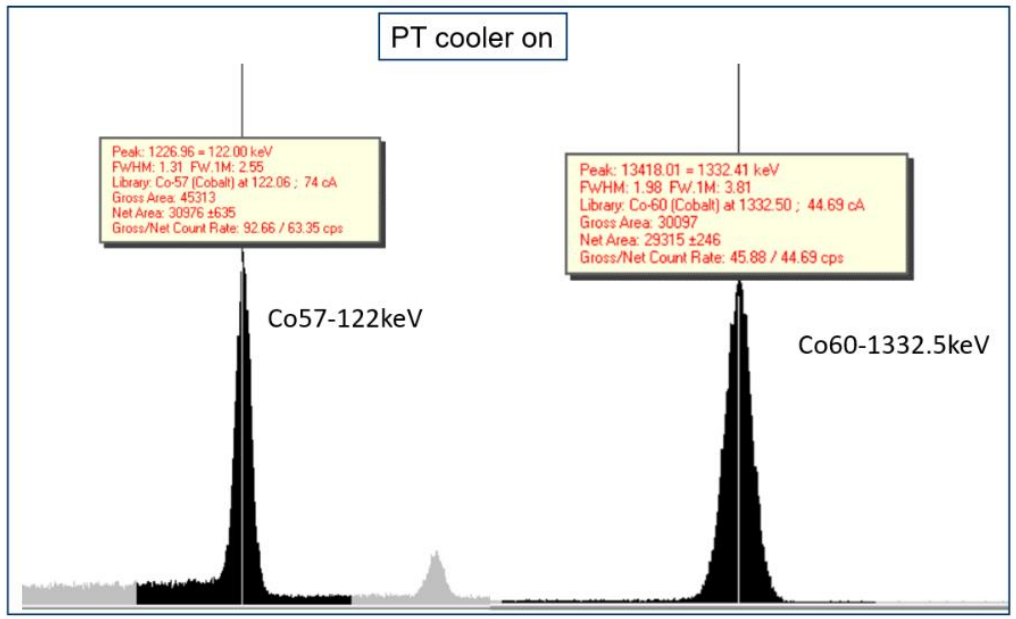

Figure 11. Co60 and Co57 energy resolution with PTC switched on.

\section{Conclusions}

In the paper, a low vibration portable PTC system for an HPGe detector was manufactured. A compressor, CVIK, and heat links were proposed to attenuate the microphone noise of detectors obtained from the PTC. The compressor vibration force was less than $0.25 \mathrm{~N}_{\mathrm{rms}}$, and the transmissibility was less than $14 \%$. The compressor vibration was greatly attenuated in the harmonic frequency region. The detector interface vibration $\mathrm{a}_{\mathrm{rms}}$ was less than 10mg. Microphone noise from the portable PTC system was undegraded by the detector energy resolution, which indicates the vibration isolation system in the study was effective in reducing the vibration level of the PTC. The detector energy resolution was degraded by $2.5 \%$ and $8.3 \%$ at $1332 \mathrm{keV}$ and $122 \mathrm{keV}$, respectively, owing to electromagnetic interference.

Author Contributions: Conceptualization, H.W.; methodology, H.W.; software, H.W.; validation, H.W., Y.X., J.C. and L.W.; formal analysis, H.W., Y.X. and J.C.; investigation, H.W. and L.W.; resources, H.W. and L.W.; data curation, H.W.; writing—original draft preparation, H.W.; writing-review and editing, H.W., Y.X. and J.C.; visualization, H.W., Y.X. and J.C.; supervision, Y.X. and J.C.; project administration, L.W.; funding acquisition, L.W. All authors have read and agreed to the published version of the manuscript.

Funding: This research was funded by National Key R\&D Program of China grant number: 2018YFB0504600 and 2018YFB0504603.

Conflicts of Interest: The authors declare no conflict of interest.

\section{References}

1. Vetter, K. Recent developments in the fabrication and operation of germanium detectors. Annu. Rev. Nucl. Part. Sci. 2007, 57, 363-404. [CrossRef]

2. Upp, D.L.; Keyser, R.M.; Twomey, T.R. New cooling methods for HPGE detectors and associated electronics. J. Radioanal. Nucl. Chem. 2005, 264, 121-126. [CrossRef]

3. Cournoyer, M.E.; Pecos, J.M.; Chunglo, S.D.; Bonner, C.; Maez, R.J. Pulse tube refrigeration for detectors. J. Radioanal. Nucl. Chem. 2013, 296, 111-115. [CrossRef]

4. Oh, H.U.; Lee, K.J.; Jo, M.S. A passive launch and on-orbit vibration isolation system for the spaceborne cryocooler. Aerosp. Sci. Technol. 2013, 28, 324-331. [CrossRef]

5. Riabzev, S.V.; Veprik, A.M.; Vilenchik, H.S.; Pundak, N.; Castiel, E. Vibration-free stirling cryocooler for high-definition microscopy. Cryogenics 2009, 49, 707-713. [CrossRef]

6. Riabzev, S.; Veprik, A.; Vilenchik, H.; Pundak, N. Control of dynamic disturbances produced by a pulse tube refrigerator in a vibration-sensitive instrumentation. Cryogenics 2009, 49, 7-11. [CrossRef]

7. Kwon, S.C.; Jeon, Y.H.; Oh, H.U. Micro-jitter attenuation of spaceborne cooler by using a blade-type hyperelastic shape memory alloy passive isolator. Cryogenics 2017, 87, 35-48. [CrossRef] 
8. Kwon, S.C.; Jo, M.S.; Ko, D.H.; Oh, H.U. Viscoelastic multilayered blade-type passive vibration isolation system for a spaceborne cryogenic cooler. Cryogenics 2020, 105, 102982. [CrossRef]

9. Ikushima, Y.; Li, R.; Tomaru, T.; Sato, N.; Suzuki, T.; Haruyama, T.; Shintomi, T.; Yamamoto, A. Ultra-low-vibration pulse-tube cryocooler system-cooling capacity and vibration. Cryogenics 2008, 48, 406-412. [CrossRef]

10. Ross, R.G., Jr. Vibration suppression of advanced space cryocoolers: An overview. In Smart Structures and Materials 2003: Damping and Isolation; International Society for Optics and Photonics: Bellingham, WC, USA, 2003; Volume 5052, pp. 1-12.

11. Yakovlev, O.; Malgin, V.; Gostilo, V.; Viba, Y. Constructive and Technological Aspects of the Development of Cryostats for HPGe Detectors with Electric Cooling. In Proceedings of the European Planetary Science Congress, Riga, Latvia, 17-22 September 2017; p. EPSC2017-112.

12. Kasahara, K.; Yamamoto, Y.; Uchiyama, T.; Miyoki, S.; Ohashi, M.; Kuroda, K.; Tomartu, T.; Suzuki, T.; Shintomi, T. Study of heat links for a cryogenic laser interferometric gravitational wave detector. In Proceedings of the International Cosmic Ray Conference, Tsukuba, Japan, 31 July-7 August 2003; Volume 5, p. 3115.

13. Pchelincev, À.; Loupilov, À.; Nurgaleev, R.; Jakovlevs, O.; Sokolov, À.; Gostilo, V.; Owens, A. A miniature compact HPGe gamma-spectrometer for space applications. J. Instrum. 2017, 12, P05017. [CrossRef]

14. Kwon, S.C.; Jeon, S.H.; Oh, H.U. Performance evaluation of spaceborne cryocooler micro-vibration isolation system employing pseudoelastic SMA mesh washer. Cryogenics 2015, 67, 19-27. [CrossRef]

15. Haug, M.; Haussmann, F.; Kellner, S.; Kern, L.; Eisenhauer, F.; Lizon, J.L.; Dietrich, M.; Thummes, G. Low vibration cooling using a pulse tube cooler and cryostat for the GRAVITY beam combiner instrument at the VLTI. In Advances in Optical and Mechanical Technologies for Telescopes and Instrumentation; International Society for Optics and Photonics: Bellingham, WC, USA, 2014; Volume 9151, p. 91513C. 